\title{
THE KEY CHAIN OF ARCHAE- OLOGY IS NOT STRONGER THAN ITS WEAKEST LINK
}

Joakim Goldhahn

We live in a changing world in which terms such as "cost efficiency" and "quality assurance" have become doxa. This is apparent to the archaeological field in general and to development-led archaeology (DA) in particular. Since the new regulations for the DA in Sweden were announced, I have noticed a rising discontent among my archaeological colleagues. This goes for researchers at the academic strongholds as well as those who work on a daily basis with DA at the National Heritage Board, museums, foundations and firms, but also those situated at the county administrations in different parts of Sweden. All seem to agree that the current system is not functioning and that something must be done.

To begin with, I find Swedish DA among the most progressive in the world. Many of the archaeological accomplishments of the last decades are not only fascinating but mind-blowing, and all in all the results of DA have significantly broadened our archaeological knowledge. This is not least manifested in the long list of academic theses that are based on the results of DA, a fact that has few parallels in the rest of the world. Simply by looking at the bookshelves in front of me, I can spot 3 I theses from the past 20 years based on DA, and the list could easily be made longer. More theses are also underway. The impact of DA is also manifested at international conferences, where archaeologists and others who work with Swedish DA are often well represented and appreciated. DA from Sweden holds a high international standard 
and status, a fact that we all should be proud of. Now, however, it appears that this good reputation is about to change, to the worse, and it seems to be happening faster than we can grasp.

Colleagues who have been harvesting in the DA field longer than I have worked as an archaeologist are now thinking of resigning, though not because of age or worn-out bodies - no, "It's just not fun anymore". The reason for their discontent is that the present practice of DA has slimmed down the framework of doing "proper archaeology" to the bare bones, and sometimes not even that. The time for preparation, fieldwork, reporting, scientific evaluation and writing is constantly decreasing. Not to mention the decreasing time for public archaeology. Meanwhile, an increasing amount of time and energy is being spent on writing well founded, scientific based applications, most of them of no use. The cheapest bid wins. The exceptions are few and must be considered to be just that: exceptions. Appeals against the decisions of the county administrations have been an unspoken rule, leading to unwanted delays and, even worse, mistrust among colleagues. This has not only affected the already hard-pressed economies of the parties concerned, but also created an unwanted burden on the already understaffed county administrative boards. Still worse, the developers who pay the bill have been suffering through these delays, with overpriced construction projects as a result. The goodwill and good name of archaeology cracks. All lose.

In a time like this, when a united archaeological corps is required, fragmentation has been the result. I have recently experienced veritable shafts between the various archaeological fields and contractors, and from what I can tell, these shafts seems to increase. I have experienced how former friends and colleagues from the past start to give each other bad names, now in the form of disguised competitors. Recently, I heard a colleague curse the fact that she could not visit a particularly interesting DA excavation simply because it was a competitive firm that performed the dig. Again: All lose.

The dissatisfaction with the new DA rules is documented and widespread. Frustration increases. It was therefore only a matter of time before the current, most relevant article from Andersson, Lagerlöf and Skyllberg would see the light.

Andersson et al. initially wonder what "good quality" stands for within DA. It's a good question. While "cost efficiency" is easy to demonstrate, since most of the time it spells less ambition and costs, "qual- 
ity assurance" is much harder to grasp. If I should speak from my own heart, and now and again that might be good, one can really wonder if the county administrations have considered this notion at all, and if so what this consideration ended in. And to be fair - and one should always be fair - one can also wonder what kind of means the county administrations have, in terms of increasing funds, when it comes to living up to the new regulations. It is not easy to make something out of nothing.

According to the new regulations, "quality" within DA is related to scientific progress. This stands in sharp contrast to the increasing lack of archaeological knowledge among the county administrations, as the authors imply. It is easy to see how this came about, not least since the archaeological knowledge is changing shape at a pace that is hard to handle. This is also evident among academics. Now and then I am asked to act as an expert on the behalf of international peer review journals, scientific assessments of manuscripts and theses, and project applications related to my own research fields. More than once I have found myself saying "no", simply because of the fact that I do not possess the specific knowledge required. Nowadays, all archaeologists do not know everything. In contrast, the more often than not understaffed county administrations are not in any position to say "no". They have to handle every issue, from the early Stone Age to the early modern period. On top of that they are expected to have an overview of the scientific progress in each and every field of archaeology. As administrators at the county administration they are expected to be omniscient. Moreover, often the project they empower has a budget that is five to ten times higher than the scientific applications submitted by distinguished researchers to the Swedish Research Council and the Bank of Sweden Tercentenary Foundation, different EU foundations, etc. The county boards' decision-making and power over the archaeological knowledge production is thus ten times larger and more comprehensive than that of representatives of the academic fields of archaeology. The only difference is that the academic evaluators have to be able to document some kind of formal academic or scientific expertise, a demand that is not required for the staff at a county administration. Is this wise, logical, reasonable?

To assess the quality of an offer is one thing, but to assess how an archaeological investigation is carried out and implemented is another matter. To be able to perform quality assurance like this requires that the 
person actively follow the steps and decisions made in the field. Today there are, to my knowledge, few or very weak routines for this. Without a doubt, the largest projects get the most attention. As for those who are supposed to perform this quality assessment in the field, often they have no time to visit the digs they should assess, no matter how much they might like to or even try. All too often the digs come to an end without any visits made at all.

In this context it is also worth noting that more and more excavations are performed during the winter months. And as anyone who has tried to excavate a grave at five degrees below zero and in 25 centimetres of snow knows, it is anything but good. Yet it happens, and nowadays all too often. What steps have been taken by the county administrative boards to ensure and assess the quality of the investigations carried out under these circumstances? Considering the new guidelines for DA, which enhance the goal of scientific progress, we might wonder why these digs are allowed at all?

Another problem with the current situation, as I see it, is that the quality assessment that is performed never seems to end in any consequences or complaints about how the hands-on archaeology was carried out. Despite numerous hair-raising examples, I can not recall any archaeological excavations or firms that received any reprimands from the county administrations. A case that I found especially upsetting was a trial excavation in the close vicinity of one of Sweden's most famous and venerable monuments. Several previous and contemporary colleagues had noted stray finds of artefacts and settlement-indicative features in the I 5,000 square meter field that was affected by plans to build residences. Within this field the DA firm that performed the trial excavation opened up two separate trial trenches, which had a combined length of 2 I meters. Not very surprisingly, they did "not find anything" and the whole area was allowed to be built on - no further antiquarian investigation was deemed necessary. This judgment was reached after opening $2 \mathrm{I}$ out of $\mathrm{I} 5,000$ square meters. The cost of this trial excavation stopped at I6,7 I 5 Swedish crowns. One third of the money at disposal was returned to the grateful developer. The whole performance took four hours. Not even one per cent of the total area was investigated. Today the same area is for sale for around I 2 million Swedish crowns. What is telling with this story is that the people in charge at the county administration did not have any objections to this ridiculous routine. The only ones who have complained are the 
people living in the vicinity who feel they have been robbed of a vital part of their history. Surely we can do better.

In line with Andersson et al., I believe that the spread of scientific results is something that ought to be discussed further. As a frequent visitor to conferences and a reader of scientific publications, I find it very easy to note that only certain parties involved in DA are conveying the scientific achievements in this way. Some of the firms seem to have made an explicit decision to skip this dialogue and use the funds to create a satisfactory surplus for their foundations or shareholders. Without naming any parties, most of them never seem to visit scientific conferences, which must be considered odd especially since they are all expected to contribute to the scientific progress through their involvement in DA. Having said this, those who are supposed to assess this scientific progress are also missing.

In the contact I have had with county administrative boards in different parts of Sweden, I have often been amazed by the embarrassing level of archaeological knowledge communicated. Of course there are exceptions to every rule, but if we consider this matter a bit further, it is a fact that the sector that has the most power over the archaeological mission has also the least knowledge of current archaeological standards, methods, theories, and, in short, the archaeological knowledge production. A fact that ought to be reflected upon.

Andersson et al. suggest several related ways to improve the outlined situation concerning DA. One way is to demand that those who mandate DA should meet the same requirements for scientific standards as those who perform the development-led archaeology. I think that all archaeologists would find this reasonable. The authors also suggest a more extended cooperation between the county administrative boards in Sweden in order to enhance their skills and broaden their all too often - regional archaeological horizon. Another way would be to introduce a "multifaceted system for quality assessment as well as a stronger organization such as a national quality evaluation council".

The last suggestion might be worth considering, but whatever path we choose to follow in the near future, I agree with the authors that something has to be done. For things to change to the better, I also think it is necessary that specific financial resources be provided for this task. To be fair: that ought to have been a requirement from the beginning when the new regulations were handed over to the county administrative boards. As things developed, they did not have a reasonable chance 
to respond to the higher standard and demands on their work that followed. If the specific financial support is not provided, I can not really see how the county administrative boards can live up to and protect the good intentions of the Heritage Conservation Act.

With this being said, I feel it is essential that all archaeologists realize that this is not just an issue for our colleagues at the county administrative boards to resolve; on the contrary, it concerns us all. If we want to see positive changes in the prevailing conditions, this is not the time to involve ourselves in any unproductive disputes on behalf of the form and content of assessed DA and whether this can be measured or not. In my opinion, this concerns all of us; we stand and fall together. The key chain of archaeology is not stronger than its weakest link. It is high time to act. 